\section{Tobacco-specific nitrosamines (TSNA) in heated tobacco product IQOS}

\section{BACKGROUND}

Heated tobacco products (HTP) have an electrical heating component, like e-cigarettes, that heats processed tobacco to $350^{\circ} \mathrm{C}$ releasing volatile components that often are not detectable in e-cigarettes. ${ }^{1}$ Although many combustion by-products may be eliminated in HTP devices, nitrosamines are generated in the process of tobacco curing rather than during combustion, and may be transferred from the HTP into the aerosol that it generates. $^{2-4}$ We hypothesised that HTP may be a significant source of tobacco-specific nitrosamines (TSNA). This pilot study determined TSNA yields in aerosol emitted from HTP in comparison to the electronic and tobacco cigarettes.

\section{METHODS}

HTP (IQOS; Amber, tobacco flavour), e-cigarettes (MarkTen; 3.5\% nicotine, tobacco flavoured) and tobacco cigarettes (Marlboro Red 100) were tested using a Borgwaldt LX-1 smoking machine following the Health Canada Intense protocol $(55 \mathrm{~mL}$ puff volume, $2 \mathrm{~s}$ duration, $30 \mathrm{~s}$ interval). Using this puffing protocol, we generated aerosol from a single HTP HeatStick (12 puffs), single tobacco

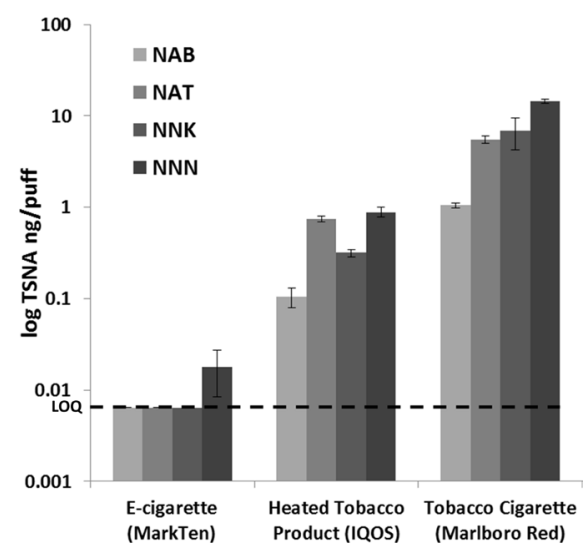

Figure 1 Yields of tobacco-specific nitrosamines (TSNA) (per puff) in aerosols generated from IQOS heated tobacco product (12 puffs/HeatStick), MarkTen e-cigarette (55 puffs) and smoke from Marlboro Red 100 combustible cigarettes (8 puffs/cigarette). The data presented are log transformed. LOQ, limit of quantitation; NAB, N'nitrosoanabasine; NAT, N'-nitrosoanatabine; NNK, 4-(methylnitrosamino)-1-(3-pyridyl)-1butanone; NNN, N'-nitrosonornicotine. cigarette (8 puffs) and from e-cigarette (55 puffs). We used different number of puffs for each product to achieve a comparable nicotine delivery across all tested products. Cambridge filters $(44 \mathrm{~mm})$ were used to capture the total particulate matter from all tested products. The control samples (blanks) were generated by passing 55 puffs of air through the filter. Cambridge filters were spiked with deuterated internal standards and extracted using $20 \mathrm{~mL} 100 \mathrm{mM}$ ammonium acetate. The following TSNAs were measured using liquid chromatography-tandem mass spectrometry: N'-nitrosoanabasine, N'-nitrosoanatabine, 4-(methylnitrosamino)-1-(3-pyridyl)-1-butanone (NNK) and N'-nitrosonornicotine (Toronto Research Chemicals; Canada). ${ }^{5}$ A limit of quantitation for each compound was $0.5 \mathrm{ng} /$ filter. Nicotine was measured using gas chromatography with nitrogen-phosphorous detector (GC-NPD) method as described previously. ${ }^{6}$ Each product was tested in triplicate. The average TSNA yields for each product were calculated per single puff and per puffing session. We used analysis of variance to test for statistical differences between the three tested products and t-tests to compare TSNA yields from HTP with yields detected in e-cigarettes and combustible cigarettes.

\section{RESULTS}

All four TSNA compounds analysed were detected in the HTP. The yields of individual TSNA per puff in the HTP aerosols were 8-22 times lower than in tobacco cigarette smoke (figure 1; all $\mathrm{p}<0.05)$. HTP delivered $1.4 \pm 0.2 \mathrm{mg}$ nicotine from a single HeatStick (12 puffs); e-cigarette $1.3 \pm 0.2 \mathrm{mg}$ per 55 puffs; and a single combustible cigarette $2.1 \pm 0.1 \mathrm{mg}$ (8 puffs). TSNA yields normalised per nicotine delivery were also significantly higher in the HTP than those found in e-cigarettes and significantly lower than those found in tobacco cigarettes, except for NNK $(p<0.05)$. TSNA yields in a single tobacco cigarette were between 7 and 17 times higher than TSNA yields in a single HTP HeatStick. No TSNAs were detected in the air control samples.

\section{CONCLUSIONS}

Like combustible products, HTPs emit substantial levels of carcinogenic TSNA. Although HTP emits lower amounts of TSNA than combustible cigarettes, the amounts are significantly higher than from e-cigarettes. Our findings are consistent with prior reports. ${ }^{347}$ One limitation of this study is that one puffing protocol was used for all devices. While this was helpful in comparing TSNA and nicotine delivery between devices, machine-based measurements are not represented of human smoking patterns or constitute intake. ${ }^{89}$ The tested HTP does not reduce emissions of an important class of tobacco carcinogens to the same degree as other commercially available technologies.

Noel J Leigh, Mary N Palumbo, Anthony M Marino, Richard J O'Connor, Maciej Lukasz Goniewicz

Department of Health Behavior, Roswell Park Comprehensive Cancer Center, Buffalo, NY, USA

Correspondence to Dr Maciej Lukasz Goniewicz, Division of Cancer Prevention and Population Sciences, Department of Health Behavior, Roswell Park Comprehensive Cancer, Buffalo, NY 14263, USA; maciej.goniewicz@roswellpark.org

Contributors MLG contributed to the conception of the work. MLG and NJL contributed to data analysis. AMM, MNP, MLG, NJL and RJO drafted the manuscript. AMM, MNP and NJL ran all experiments. All authors approved the final version of the manuscript. MLG has full access to all study data and takes responsibility for the integrity of the data and accuracy of the data analysis.

Funding Research reported in this publication was supported by the National Cancer Institute of the National Institutes of Health under award numbers P01 CA200512 and P30 CA016056.

Disclaimer The content is solely the responsibility of the authors and does not necessarily represent the official views of the National Institutes of Health.

Competing interests MLG reports grants from and served as an advisory board member to pharmaceutical companies that manufacture smoking cessation drugs. RJO was a member of the FDA Tobacco Products Scientific Advisory Committee, which considered Philip Morris International's modified risk application for IQOS in January 2018. Other authors declare no conflict of interest.

Patient consent Not required.

Provenance and peer review Not commissioned; externally peer reviewed.

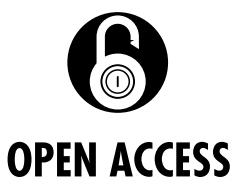

Open access This is an open access article distributed in accordance with the Creative Commons Attribution Non Commercial (CC BY-NC 4.0) license, which permits others to distribute, remix, adapt, build upon this work non-commercially, and license their derivative works on different terms, provided the original work is properly cited and the use is non-commercial. See: http:// creativecommons.org/licenses/by-nc/4.0/

(C) Article author(s) (or their employer(s) unless otherwise stated in the text of the article) 2018. All rights reserved. No commercial use is permitted unless otherwise expressly granted. 
To cite Leigh NJ, Palumbo MN, Marino AM, et al. Tob Control 2018;27:s37-s38.

Received 16 February 2018

Revised 17 May 2018

Accepted 18 May 2018

Published Online First 21 September 2018

Tob Control 2018;27:s37-s38.

doi:10.1136/tobaccocontrol-2018-054318

\section{REFERENCES}

1 Goniewicz ML, Knysak J, Gawron M, et al. Levels of selected carcinogens and toxicants in vapour from electronic cigarettes. Tob Control 2014;23:133-9.
2 Hecht SS, Biochemistry HSS. Biochemistry, biology, and carcinogenicity of tobacco-specific $\mathrm{N}$-nitrosamines. Chem Res Toxicol 1998;11:559-603.

3 Schaller JP, Keller D, Poget L, et al. Evaluation of the Tobacco Heating System 2.2. Part 2: Chemical composition, genotoxicity, cytotoxicity, and physical properties of the aerosol. Regul Toxicol Pharmacol 2016;81 Suppl 2:S27-S47.

4 Bekki K, Inaba Y, Uchiyama S, et al. Comparison of chemicals in mainstream smoke in heat-notburn tobacco and combustion cigarettes. J Uoeh 2017;39:201-7.

5 Coresta recommended method $N^{\circ} 75$. https://www. coresta.org/sites/default/files/technical_documents/ main/CRM_75-updateJuly14.pdf 2014.
6 Goniewicz ML, Kuma T, Gawron M, et al. Nicotine levels in electronic cigarettes. Nicotine Tob Res 2013;15:158-66.

7 St.Helen G, Jacob III P, Nardone N, et al. IQOS: examination of Philip Morris International's claim of reduced exposure. Tob Control 2018;27(Suppl1):s30 $-s 36$.

8 Adamson J, Azzopardi D, Errington G, et al. Assessment of an in vitro whole cigarette smoke exposure system: The Borgwaldt RM20S 8-syringe smoking machine. Chem Cent J 2011;5:50.

9 Counts ME, Morton MJ, Laffoon SW, et al. Smoke composition and predicting relationships for international commercial cigarettes smoked with three machine-smoking conditions. Regul Toxicol Pharmacol 2005;41:185-227. 